\title{
O Marketing de Relacionamento com o Cidadão como instrumento da análise Ética da Pesquisa
}

The Relationship Marketing with the Citizen as an instrument of Ethical Analysis of Research

SANTOS, Marcos Antonio Batista dos. Graduado em Alimentos

Instituto Federal de Educação Ciência e Tecnologia do Sertão Pernambucano - Reitoria, Anexo 1 - Rua Valério Pereira, 72

Centro Petrolina-PE. BRASIL. CEP: 56304-060. Email: marcos.antonio@ifsertao-pe.edu.br

SILVA, Marcio Bonfim. Especialista em Marketing Estratégico

Centro de Cultura João Gilberto, Rua José Petitinga s/n, Juazeiro-BA. CEP 48903-010. Email: mfabiano41@gmail.com

\section{RESUMO}

0 presente trabalho tem como objetivo fazer uma análise do marketing de relacionamento com o cidadão aplicado à análise ética da pesquisa envolvendo seres humanos por um sistema integrado de órgãos pertencentes à administração pública, com fins de proteção dos direitos dos participantes da pesquisa. Esse sistema atua de forma integrada e sob orientação de uma comissão superior, mediante a utilização de um sistema de informação capaz de processar informações; bem como, armazená-las, constituindo autêntico banco de dados de acesso público. Nesse contexto, um desses órgãos desempenha suas funções no âmbito de uma autarquia educacional localizada no município de Petrolina-PE; embora composto por servidores dessa autarquia, a atuação desse colegiado é independente quanto aos interesses daquela, consubstanciando num instrumento de defesa de direitos dos participantes da pesquisa.

Palavras-chave: Ética; Pesquisa; Análise; Cidadão

\begin{abstract}
The present work aims to make an analysis of relationship marketing with the citizen applied to the ethical analysis of research involving human beings by an integrated system of organs belonging to the public administration, with the purpose of protecting the rights of research participants. This system operates in an integrated manner and under the guidance of a higher commission, through the use of an information system capable of processing information; as well as storing them, constituting an authentic database of public access. In this context, one of these bodies performs its functions within the scope of an educational autarchy located in the municipality of Petrolina PE; although composed of servers of this autarchy, the performance of this collegiate is independent of its interests, consubstantiating an instrument of defense of the rights of the participants of the research.
\end{abstract}

Keywords: Ethics; Search; Analysis; Citizen. 
SANTOS, M. A. B.; SILVA, M. B. (2018)

O Marketing de Relacionamento com o Cidadão como instrumento da análise Ética da Pesquisa

\section{Introdução}

Com o advento da emenda constitucional $n^{\circ} 19 / 98$, o constituinte buscou aproximar a administração pública da população que necessita de seus serviços, mediante a inserção no texto constitucional do princípio da eficiência. Nesse sentido, a administração pública deve afastar-se do modelo burocrático de atuação com ênfase em normas e procedimentos, em detrimento ao atendimento dos cidadãos; e passa a adotar um modelo gerencial com ênfase no atendimento a esse público que passa a ser considerado como cliente.

Corroborando com esse entendimento, a administração pública gerencial baseia-se no conceito de eficiência e atuação descentralizada com foco no atendimento do cidadão (ARAÚJO; PEREIRA, 2012).

Segundo Batista (2011) "A utilização de diferentes e inovadoras práticas de gestão pública transformou o modo com que o governo se relaciona com o cidadão." (apud DEMO; PESSÔA, 2015).

Corroborando com esse entendimento de Lara e Goslling (2016) a utilização das novas tecnologias da informação e comunicação (TIC) na prestação dos serviços públicos, deu novo impulso à Gestão Pública, a partir do final dos anos 90.

Nesse contexto, a gestão do relacionamento com o cidadão, adaptada do marketing de relacionamento aplicado à iniciativa privada, busca "promover a melhoria dos serviços públicos e a aproximação dos gestores públicos às necessidades do cidadão [...] no tocante à prestação de serviços públicos" (LARA; GOSLLING, 2016 p. 335).

Com efeito, a construção desses relacionamentos entre órgãos governamentais e pessoas torna as respectivas relações mais justas, pautadas pelo princípio constitucional da igualdade. A respeito disso, esses relacionamentos consubstanciam numa autêntica forma de exercício da cidadania, a qual consiste no pleno gozo dos direitos fundamentais prescritos na constituição federal da república; sobretudo, os direitos civis.

A respeito desses relacionamentos, no âmbito do ministério da saúde, existe o sistema CEP/CONEP encarregado por instituir a regulamentação ética das pesquisas envolvendo seres humanos desenvolvidas no Brasil, o qual será objeto de análise no decorrer deste trabalho. De acordo com demonstrativo do conselho nacional de saúde ${ }^{1}$, esse sistema é composto por setecentos setenta e um (771) colegiados espalhados pelo território nacional.

Nesse contexto, a compreensão da relação entre o supracitado sistema com o seu públicoalvo contribuirá para uma produção científica ética no que tange aos direitos dos participantes da pesquisa.

Nesse aspecto, de suma importância o despertar das instituições científicas e acadêmicas sobre essa relação, com fins de engajar seus pesquisadores na busca de um conhecimento pautado pelo respeito ao ser humano; sobretudo, nas cidades de Juazeiro e Petrolina.

A respeito dessas cidades, esse trabalho torna-se relevante. Pois, Juazeiro e Petrolina, segundo o $\mathrm{MEC}^{2}$, concentram mais noventa (90) cursos de nível superior em atividade, entre

1 Disponível em:<http://www.conselhosaude.gob.br_comissoes/cone/index.html. Acesso em 31 de julho de 2017.

2 Disponível em: < http:///emec.mec.gov.br. Acesso em 31 de julho de 2017. 
SANTOS, M. A. B.; SILVA, M. B. (2018)

O Marketing de Relacionamento com o Cidadão como instrumento da análise Ética da Pesquisa

instituições públicas e privadas, constituindo uma região com considerável produção científica; sendo assim, fazendo-se necessária a aproximação dessas instituições do sistema CEP/CONEP.

Nesse diapasão, inserem-se os cursos superiores da Faculdade São Francisco de Juazeiro; especialmente, o curso de especialização Gestão Empresarial e Marketing cujo objeto de estudo situa-se em ciências direcionadas ao ser humano.

Ademais, importante ressaltar a importância do presente trabalho para seu autor, considerando sua atuação como secretário administrativo de um desses colegiados supracitados; sobretudo, como pesquisador e agente de difusão da importância da ética sobre a pesquisa que envolva seres humanos.

\section{Fundamentação Teórica}

Segundo Reis (2002, p.11-12) "o marketing é a defesa de um melhor relacionamento entre quem oferece uma proposta e quem a recebe". Para tanto, faz-se uma melhor compreensão das necessidades e anseios de eventual consumidor.

Possuindo suas origens nas relações entre o consumidor e a empresa, o conceito de marketing adquiriu várias facetas; contudo, importante mencionar o marketing de relacionamento que segundo Kotler e Armstrong (2006) baseia-se na criação, manutenção e aprimoramento de fortes relacionamentos com clientes e interessados.

Segundo Saliby (1997, p. 7) "Na abordagem do marketing de relacionamento, os clientes deixam apenas de números ou marketshare e passam a ser parte integrante da organização". Prosseguindo, o mesmo autor afirma "Seu conceito está ligado à ideia de 'trazer o cliente' para dentro da organização". Dessa forma, há uma participação efetiva desse cliente na criação de serviços e produtos.

"Esse tipo de marketing pode ser interpretado como um investimento feito pela empresa em seus clientes, visando como retorno atingir a satisfação e a fidelidade destes" (SALIBY, 1997, p. 7). Dessa forma, visando um relacionamento de longo prazo pautado na compreensão e atendimentos dos clientes.

Partindo da premissa da adoção do modelo gerencial pela administração pública brasileira, voltado ao atendimento das necessidades dos cidadãos clientes, surge a gestão do relacionamento com o cidadão na prestação de serviços públicos. Esse modelo de gestão possui a mesma ideia central do marketing de relacionamento: estabelecimento de relacionamento em longo prazo com o cidadão na prestação de algum serviço ou produto.

A competitividade é traço marcante no universo da iniciativa privada devido à grande disponibilidade de serviços e produtos ofertados aos clientes, diferentemente ocorre quanto à iniciativa pública que não possui concorrentes na prestação de seus serviços, fato que implica em uma fidelização do cliente de forma compulsiva. Portanto, faz-se necessário que a iniciativa pública desenvolva continuamente técnicas de relacionamento com o cidadão.

Reis (2002) afirma que o estado poderá fomentar o marketing cultural de forma direta e indireta. Ao atuar de forma direta, faz às vezes de agente cultural, realizando projetos que the parece 
SANTOS, M. A. B.; SILVA, M. B. (2018)

O Marketing de Relacionamento com o Cidadão como instrumento da análise Ética da Pesquisa

fundamental; e de forma indireta, incentiva a participação privada por meio de fomento à produção cultural do país, mediante leis de incentivo cultural.

De forma análoga ao exposto, a administração pública pode fomentar o marketing de relacionamento com o cidadão. Ao criar órgãos, instituições ou entidades responsáveis pela execução dos serviços públicos; a administração pública poderá instituir canais de comunicação entre àquelas e o público que usufruirá de seus serviços, como ocorre, por exemplo, com a lei ${ }^{\circ}$ $12.527 / 2011$.

Essa lei entrou criou formas de acesso à informações públicas tanto para pessoas físicas, quanto para pessoas jurídicas. (BRASIL 2011).

Gonçalves e Filho (1995) afirmam que informação é hoje poderoso recurso das organizações, permitindo a estas o perfeito alinhamento estratégico mediante constantes fluxos bidirecionais entre a empresa e o macroambiente, e criando condições para que se viabilizem seus objetivos e se cumpra sua missão corporativa.

Nesse sentido, o marketing de relacionamento com o cidadão proporciona excelente ferramenta de aperfeiçoamento dos órgãos e instituições públicas de forma eficiente como preceituado na constituição federal e nas leis de suas criações com fins de satisfação do interesse público.

\subsection{Sistema CEP/CONEP}

Barbosa, Corrales e Sillbermann (2014) explicam que "a relação entre ciência, tecnologia e ética merece especial atenção no que concerne ao controle social da pesquisa, pois as pesquisas têm grande importância para o desenvolvimento social, científico e econômico de um país".

Nesse contexto de controle social sobre as pesquisas no Brasil, Schuch e Victora (2015) afirmam que a Resolução no 196/96-CNS (Conselho Nacional de Saúde) foi elaborada com a finalidade da criação dos Comitês de Ética em Pesquisa (CEPs), o consentimento informado (chamado posteriormente de Termo de Consentimento Livre e Esclarecido) e a Comissão Nacional Ética em Pesquisa (CONEP) sob o Conselho Nacional de Saúde (CNS) do Ministério da Saúde.

Dessa forma, constituindo sistema integrado de órgãos governamentais com fins de revisão ética de pesquisas envolvendo seres humanos, conforme o organograma a seguir:

Quadro 01- organograma do sistema CEP/CONEP.

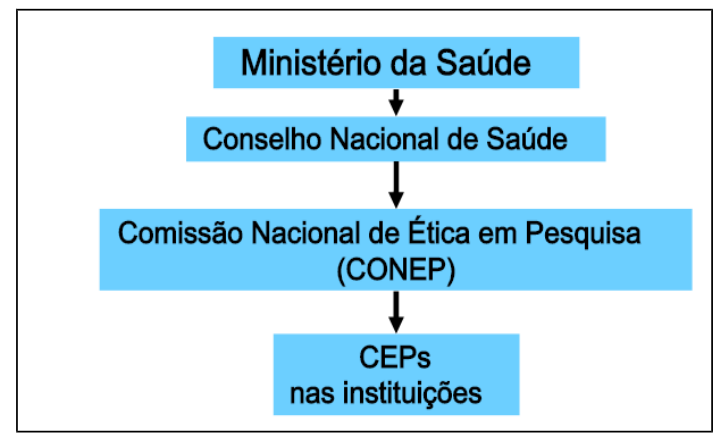

Fonte: Comitê de Ética em Pesquisa do centro universitário do estado do Pará 
SANTOS, M. A. B.; SILVA, M. B. (2018)

O Marketing de Relacionamento com o Cidadão como instrumento da análise Ética da Pesquisa

Essa resolução orienta sobre aspectos éticos a serem observados nos protocolos de pesquisa e contempla aspectos operacionais quanto à estruturação de um sistema em rede para acompanhamento da ética na pesquisa.

O sistema criado a partir dessa resolução constitui, conforme Gonçalves e Filho (1995, p. 2231) constituem "uma organização em rede, resultantes de alianças estratégicas e outros tipos de associações que atuam como uma forma de coalizão frouxa e flexível guiada por um núcleo".

A respeito disso, a resolução $n^{\circ} 466 / 2012-C N S$ no item VII informa que o sistema CEP/CONEP é integrado pela Comissão Nacional de Ética em Pesquisa - CONEP/CNS/MS do Conselho Nacional de Saúde e pelos Comitês de Ética em Pesquisa - CEP - compondo um sistema que utiliza mecanismos, ferramentas e instrumentos próprios de inter-relação, num trabalho cooperativo que visa, especialmente, à proteção dos participantes de pesquisa do Brasil, de forma coordenada e descentralizada por meio de um processo de acreditação.

Nesse sentido, a comissão nacional de ética, uma instância colegiada, de natureza consultiva, educativa e formuladora de diretrizes e estratégias no âmbito do Conselho Nacional de Saúde (BRASIL 2017).

Essa mesma resolução no item VII.2 afirma que os CEP são colegiados interdisciplinares e independentes, de relevância pública, de caráter consultivo, deliberativo e educativo, criados para defender os interesses dos participantes da pesquisa em sua integridade e dignidade e para contribuir no desenvolvimento da pesquisa dentro de padrões éticos.

Esses órgãos regionais atuam mais próximos aos pesquisadores e participantes da pesquisa exercendo as funções de aprovação e acompanhamento das pesquisas, recebimento de notificação de eventos adversos durante execução das pesquisas, realização de eventos educativos sobre a ética em pesquisa, trabalhos educativos. Importante ressaltar que esses colegiados tornam-se corresponsáveis pelas pesquisas que thes são submetidas, quando posteriormente aprovadas.

Todas essas funções são desempenhadas sob a coordenação e orientação da CONEP. Os comitês de ética em pesquisa articulam-se à comissão nacional de ética em pesquisa seguindo as orientações emanadas dessa comissão com fins de fluxo de informações e padronização dos critérios de controle social aplicáveis à pesquisa.

Corroborando com esse entendimento, a norma operacional $n^{\circ} 01 / 2013-$ CNS preceitua que a CONEP deve se articular a esse sistema (BRASIL 2013).

Esse sistema possui como público-alvo os pesquisadores (nacionais e estrangeiros) e, sobretudo, os participantes da pesquisa. Nesse sentido, o sistema CEP/CONEP proporciona aos pesquisadores um padrão ético em suas pesquisas, pautado no respeito aos participantes da pesquisa, independente da área de conhecimento; aos participantes da pesquisa, esse sistema possui a finalidade de preservar os seus direitos, evitando que sejam submetidos a procedimentos vexatórios ou invasivos, durante a pesquisa, que possam ferir sua dignidade.

\subsection{Sistema Plataforma Brasil}


SANTOS, M. A. B.; SILVA, M. B. (2018)

O Marketing de Relacionamento com o Cidadão como instrumento da análise Ética da Pesquisa

Com fins de subsidiar o marketing de relacionamento a esses cidadãos específicos (pesquisadores e participantes da pesquisa) de forma efetiva, imprescindível utilização de um sistema de informação, que segundo Gonçalves e Filho (1995, p. 23-31) "são sistemas capazes de reunir, selecionar, avaliar e distribuir as informações necessárias e precisas".

Dessa forma, essa modalidade de marketing de relacionamento torna-se uma excelente ferramenta para compreender e satisfazer as necessidades desses cidadãos sob a ótica da pesquisa científica pautada pela ética.

O processo de regulamentação da ética em pesquisa no Brasil, por um sistema de órgãos governamentais, requer padronização e fluxo permanente de informações, além de consolidação dessas informações para uma célere consulta (SCHUCH; VICTORA, 2015).

Considerando esse pressuposto, fundamental a criação de um sistema de informação capaz de consolidar as informações relativas às pesquisas que envolvam seres humanos, sendo também capaz de proporcionar um canal de comunicação com o público interessado.

Nesse aspecto, vale a pena considerar a descrição dos objetivos da Plataforma Brasil (SCHUCH; VICTORA, 2015): A Plataforma Brasil é uma base nacional e unificada de registros de pesquisas envolvendo seres humanos para todo o sistema CEP/CONEP. Ela permite que as pesquisas sejam acompanhadas em seus diferentes estágios - desde sua submissão até a aprovação final pelo CEP e pela CONEP, quando necessário - possibilitando inclusive o acompanhamento da fase de campo, o envio de relatórios parciais e dos relatórios finais das pesquisas (quando concluídas). [...] O sistema permite, ainda, a apresentação de documentos também em meio digital, propiciando ainda à sociedade o acesso aos dados públicos de todas as pesquisas aprovadas. Pela Internet é possível a todos os envolvidos o acesso, por meio de um ambiente compartilhado às informações em conjunto diminuindo de forma significativa o tempo de trâmite dos projetos em todo o sistema CEP/CONEP (BRASIL, 2012).

Nessa concepção, Gonçalves e Filho (1995) explicam que sistemas de informação para a gerência do relacionamento com os clientes são sistemas planejados, construídos e administrados de modo a maximizar a sintonia e o relacionamento entre a organização e seus clientes, permitindo a recepção e manutenção de informações sobre os clientes.

Prosseguindo, os mesmos autores afirmam que "esses sistemas são compostos por bancos de dados e de programas de computador (sistemas aplicativos) construídos de modo a aperfeiçoar o relacionamento com o cliente".

Diante do exposto, a Plataforma Brasil é o sistema de informação desenvolvido com os fins de relacionamento com o cidadão pesquisador visando à proteção dos participantes da pesquisa. Além disso, proporciona a regulamentação ética da pesquisa.

A respeito disso, "a Plataforma Brasil unifica os registros de pesquisa, o acompanhamento, pelos CEPs e CONEP, de todo o processo de pesquisa e o acesso, à sociedade, aos dados públicos das pesquisas aprovadas" (SCHUCH; VICTORA, 2015, p.781-782); dessa forma, materializando os canais de comunicação preceituados pela lei $n^{\circ}$ 12.527/2011.

Através desse sistema informatizado é realizado trabalho de regulamentação ética da pesquisa. Mediante esse meio de comunicação, os pesquisadores poderão: 
SANTOS, M. A. B.; SILVA, M. B. (2018)

O Marketing de Relacionamento com o Cidadão como instrumento da análise Ética da Pesquisa

1. Submeter suas pesquisas à análise ética,

2. Inserir documentos pertinentes à pesquisa;

3. Acompanhar a tramitação do processo de análise ética da pesquisa;

4. Acessar os pareceres elaborados pelos comitês referentes à sua pesquisa;

5. Interpor recursos contra decisão quando da não aprovação de sua pesquisa.

Nesse mesmo sistema e com fins de regulamentação ética, os comitês de ética desempenharão suas atividades de:

1. Recepção e validação documental com fins de averiguar a conformidade dos documentos pertencentes à pesquisa inseridos pelo pesquisador;

2. Distribuição interna dos projetos de pesquisa, entre os membros do colegiado, para fins de elaboração de parecer individual;

3. Elaboração do parecer consubstanciado durante as reuniões;

4. Registro de reuniões.

Com fins de uma melhor assimilação do processo de regulamentação ética, através da Plataforma Brasil, a figura adaptada a seguir esquematiza os procedimentos envolvidos na análise ética de um projeto de pesquisa, bem como os atores envolvidos:

Quadro 02 - fluxograma da apreciação ética da pesquisa via plataforma Brasil

\begin{tabular}{|c|c|}
\hline \multirow{3}{*}{ Pesquisador } & 1. Cadastro na Plataforma Brasil \\
\hline & 2. Cadastro do protocolo/ Gestão da pesquisa/ Recurso \\
\hline & 3. Envio para o CEP Em recepção e Validação pelo CEP \\
\hline \multirow{2}{*}{$\underline{\text { Secretaria do cep. }}$} & 1. Recebimento do protocolo/ Gestão da pesquisa/ Recursos \\
\hline & 2. Indicação da Relatoria \\
\hline $\begin{array}{l}\text { Coordenador } \\
\text { do cep. }\end{array}$ & 1. Confirmação da Indicação da Relatoria \\
\hline Relator & Confecção de parecer individual \\
\hline \multirow[t]{2}{*}{ colegiado } & $\begin{array}{l}\text { 1. Apreciação da Relatoria: Aprovado. Pendente, Não aprovado ou Retirado } \\
\text { 2. Liberação do Parecer }\end{array}$ \\
\hline & 3. Apreciação do Colegiado (votação) \\
\hline Coordenador & Emissão do Parecer Consubstanciado \\
\hline
\end{tabular}

Fonte: comitê de ética em pesquisa do centro universitário do Pará

Conforme demonstrado, o acesso a esse sistema é condicionado ao cadastro prévio do pesquisador através da inserção de suas informações pessoais e profissionais. A partir desse momento, o pesquisador poderá submeter seu projeto de pesquisa à análise ética por um comitê.

Ainda sobre a análise da figura, evidencia-se que o trabalho desenvolvido pelo comitê de ética culmina no parecer consubstanciado elaborado pelo coordenador do colegiado, após a elaboração do parecer individual de um relator membro o qual é objeto de discussão entre os membros do colegiado, presentes a respectiva reunião. A respeito disso, o resultado do parecer individual não vincula o resultado do parecer do colegiado, portanto é possível um parecer individual recomendar a não aprovação do projeto de pesquisa, enquanto o parecer consubstanciado 
SANTOS, M. A. B.; SILVA, M. B. (2018)

O Marketing de Relacionamento com o Cidadão como instrumento da análise Ética da Pesquisa

recomendar sua aprovação ou apontar a existência de pendências a serem sanadas pelos pesquisadores e vice-versa.

Diante do exposto, a Plataforma Brasil, no contexto do sistema CEP/CONEP, constitui o principal canal de comunicação entre a administração pública e os cidadãos. Essa ferramenta proporciona um marketing de relacionamento no qual o pesquisador possui acesso aos procedimentos de análise ética de sua pesquisa, garantido pelo processo de interação com o comitê de ética responsável, sempre com fins de proteger os direitos dos participantes da pesquisa.

\subsection{Comitê de Ética em Pesquisas com Seres Humanos do IF Sertão-PE}

Os comitês de ética em pesquisa são colegiados interdisciplinares que devem existir nas instituições públicas e privadas que realizam pesquisas envolvendo seres humanos no Brasil, criados para defender os interesses dos participantes da pesquisa (BRASIL 2006).

Nesse sentido, no âmbito do Instituto Federal de Educação, Ciência e Tecnologia do Sertão Pernambucano (IF Sertão PE), funciona, de forma integrada ao sistema CEP/CONEP, o Comitê de Ética em pesquisa envolvendo seres humanos do IF Sertão PE (BRASIL 2015).

Considerando a missão institucional dessa autarquia educacional: Ensino, Pesquisa e Extensão; torna-se propícia a presença de um comitê de ética em pesquisa junto a sua estrutura.

Com fins de subsidiar a regulamentação ética, essa autarquia educacional fornece a infraestrutura necessária ao funcionamento do CEP IF Sertão PE, embora esse colegiado não esteja subordinado às diretrizes do IF Sertão PE, pois o processo de análise ética das pesquisas requer colegiados independentes.

Essa independência torna-se essencial para o cumprimento da missão do CEP IF Sertão PE: "salvaguardar os direitos e a dignidade dos sujeitos da pesquisa" (BRASIL, 2006), porquanto projetos de pesquisas não poderão submeter os sujeitos da pesquisa a procedimentos invasivos ou vexatórios. Sendo assim, a atuação desse colegiado deve estar isenta dos interesses institucionais do IF SertãoPE.

Corroborando com esse entendimento, a composição desse colegiado busca a representação de todas as unidades dessa autarquia educacional, conforme o art. $4^{\circ}$ do regimento interno desse colegiado: O CEP do IF Sertão-PE será composto de, pelo menos, dez membros titulares com seus respectivos suplentes, incluindo a participação de profissionais das diversas áreas: saúde, ciências exatas, sociais e humanas que envolvam todos os Campus do IF Sertão-PE, e dois membros externos ligados à pesquisa com seres humanos.

Além disso, em obediência ao preconizado na resolução n² 240/1997-CNS o CEP IF Sertão-PE possui membros representativos do Sistema Único de Saúde.

Nesse contexto, o CEP IF Sertão-PE, dentro do sistema CEP/CONEP, exerce suas atribuições sob orientações emanadas da CONEP. Nesse sentido, a resolução n 466/ 2012- CNS, no item VIII, elenca suas atribuições:

1. Avaliar protocolos de pesquisa envolvendo seres humanos, com prioridade nos temas de relevância pública e de interesse estratégico da agenda de prioridades do SUS, com base nos 
SANTOS, M. A. B.; SILVA, M. B. (2018)

O Marketing de Relacionamento com o Cidadão como instrumento da análise Ética da Pesquisa

indicadores epidemiológicos, emitindo parecer, devidamente justificado, sempre orientado, dentre outros, pelos princípios da impessoalidade, transparência, razoabilidade, proporcionalidade e eficiência, dentro dos prazos estabelecidos em norma operacional, evitando redundâncias que resultem em morosidade na análise;

2. Desempenhar papel consultivo e educativo em questões de ética;

3. Elaborar seu Regimento Interno.

Entretanto, "essa resolução foi concebida com fins de regulamentação ética das pesquisas biomédicas que costumam firma-se na em pretensa neutralidade" (BARBOSA; CORRALES; SILLBERMANN, 2014 p. 481-483).

Prosseguindo, esses mesmos autores afirmam que "os métodos e procedimentos empíricos das ciências humanas e sociais são tidos como inerentemente éticos". Dessa forma, pressupõe uma relação de confiança entre pesquisador e participante da pesquisa.

Embora o sistema CEP/CONEP, regido pela resolução $n^{\circ}$ 196/96 posteriormente revogada pela resolução $n^{\circ} 466 / 12$, represente um avanço no controle social da pesquisa, ainda havia lacunas dentro desse sistema quanto à análise ética das pesquisas das ciências humanas e sociais.

Com o intuito do preenchimento dessas lacunas, foi editada a resolução $n^{\circ}$ 510/2016- CNS que a assim dispõe em seu art. $1^{\circ}$ : Esta Resolução dispõe sobre as normas aplicáveis a pesquisas em Ciências Humanas e Sociais cujos procedimentos metodológicos envolvam a utilização de dados diretamente obtidos com os participantes ou de informações identificáveis ou que possam acarretar riscos maiores do que os existentes na vida cotidiana, na forma definida nesta Resolução (BRASIL 2016).

Essa norma possui caráter complementar coexistindo com a resolução $n^{\circ} 466 / 12$-CNS para reger a atuação do sistema CEP/CONEP.

Com efeito, o CEP IF Sertão-PE exerce suas competências, predominantemente, sobre os projetos de pesquisas sob autoria de pesquisadores vinculados ao IF Sertão-PE que em sua maioria atuam nessas áreas do conhecimento.

Além disso, o CEP IF Sertão-PE também avalia, sobre o aspecto ético, projetos de pesquisas pertencentes a pesquisadores não vinculados ao IF Sertão-PE.

Diante do exposto, ressaltar que a atuação de um comitê de ética restringe-se ao elemento ético da pesquisa, conforme art. 25 da resolução $n^{\circ}$ 510/16-CNS: “A avaliação a ser feita pelo Sistema CEP/CONEP incidirá sobre os aspectos éticos dos projetos, considerando os riscos e a devida proteção dos direitos dos participantes da pesquisa." Prosseguindo com análise da resolução em comento, o seu $\$ 1^{\circ}$ do art. 25 assim dispõe: A avaliação científica dos aspectos teóricos dos projetos submetidos a essa Resolução compete às instâncias acadêmicas específicas, tais como comissões acadêmicas de pesquisa, bancas de pós-graduação, instituições de fomento à pesquisa, dentre outros. Não cabe ao Sistema CEP/CONEP a análise do desenho metodológico em si.

Dessa forma, os projetos de pesquisa oriundos do IF Sertão-PE são avaliados sobre o aspecto ético pelo CEP IF Sertão-PE, e sobre os procedimentos científicos pelo comitê científico do IF Sertão-PE. Ressaltando que as atuações desses colegiados não se vinculam uma a outra, ou seja, 
SANTOS, M. A. B.; SILVA, M. B. (2018)

O Marketing de Relacionamento com o Cidadão como instrumento da análise Ética da Pesquisa

uma aprovação do projeto de pesquisa pelo comitê científico não implicará sua aprovação perante o CEP IF Sertão-PE, vice-versa.

Além disso, quando necessário e com fins de proteção do participante da pesquisa, o CEP IF Sertão-PE poderá avaliar os procedimentos científicos da pesquisa, conforme preconiza o $\S 2^{\circ}$ do art. 26 da resolução em comento "A avaliação a ser realizada pelo Sistema CEP/CONEP incidirá somente sobre os procedimentos metodológicos que impliquem em riscos aos participantes".

De fato, a pesquisa científica para ser considera ética em seus métodos empregados, deverá respeitar os seguintes princípios, conforme descritos pelo Manual de Ética em Pesquisa com Seres Humanos (BRASIL 2004):

1. Autonomia: Significa que a pessoa tem o direito de decidir se quer participar de uma pesquisa ou não. Para respeitar esse princípio é necessário que o pesquisador solicite o consentimento por escrito da pessoa que participará do estudo. Esse consentimento deve livre e esclarecido. Ou seja, a pessoa deve decidir por si mesma se quer participar, após saber exatamente o que aquela pesquisa está investigando e o que significa aceitar, o que o pesquisador vai fazer com os participantes;

2. Beneficência: o pesquisador deve sempre buscar o bem, isto é, fazer algo que possa trazer benefícios. 0 bem-estar das pessoas que participam da pesquisa deve estar acima dos interesses da ciência e da sociedade. As pesquisas devem ser relevantes e ter utilidade social e científica;

3. Não maleficência: o pesquisador não deve fazer nada que cause mal ou problemas para os participantes da pesquisa. Deve garantir que os riscos previsíveis sejam evitados e prestar assistência quando causar dano decorrente da participação na pesquisa;

4. Justiça: todas as pessoas podem ser participantes de pesquisas e devem ter acesso aos benefícios dos seus resultados. Não se justifica que as pesquisas sejam realizadas com pessoas carentes e que seus resultados benéficos retornem apenas para as pessoas que podem pagar por eles.

O cumprimento desses quatro princípios, no âmbito das pesquisas científicas, visa impedir os abusos cometidos contra os participantes da pesquisa. Logo, o CEP IF Sertão-PE ao apreciar o projeto de pesquisa, na verdade busca constatar se os quatro princípios estão inseridos nos procedimentos científicos.

Sendo assim, o objetivo desse trabalho é analisar o marketing de relacionamento com o cidadão aplicado no âmbito de um sistema integrado de órgãos pertencentes à administração pública (Ministério da Saúde), cuja finalidade é a análise ética da pesquisa como instrumento de defesa dos direitos dos participantes da pesquisa.

Para tanto, será realizada análise do desempenho das atribuições do CEP IF Sertão-PE, através da análise do seu perfil no sistema de informação Plataforma Brasil, criado com fins de subsidiar o marketing de relacionamento entre o pesquisador e o CEP IF Sertão-PE. 


\section{Método}

Trata-se de uma pesquisa descritiva realizada mediante análise das principais normas e resoluções concernentes ao sistema CEP/CONEP; bem como, foram consultados artigos científicos publicados acerca do sistema CEP/CONEP.

Ademais, também foram objetos de análise artigos científicos e livros sobre sistemas de informação e marketing de relacionamento, devido à estreita relação dessas áreas do conhecimento com o desenvolvimento das atividades do sistema CEP/CONEP.

Com o fim de averiguar a aplicação prática das normas e resoluções pesquisadas, foi realizada uma visita à secretaria administrativa do CEP IF Sertão-PE; dessa forma, foi analisado o desempenho desse órgão à luz dessas normas e resoluções que regem sua atuação dentro do sistema CEP/CONEP.

\section{Resultados e Discussão}

O CEP IF Sertão-PE iniciou suas atividades no ano de dois mil e dezesseis (2016), quando teve seu registro devidamente aprovado pela CONEP. A partir desse momento e integrado ao sistema CEP/CONEP, realizou a análise de sessenta e nove (69) projetos de pesquisa, culminando numa aprovação ética de treze projetos, conforme a figura a seguir:

Quadro 03 - Índices de produção CEP IF Sertão-PE ano 2016

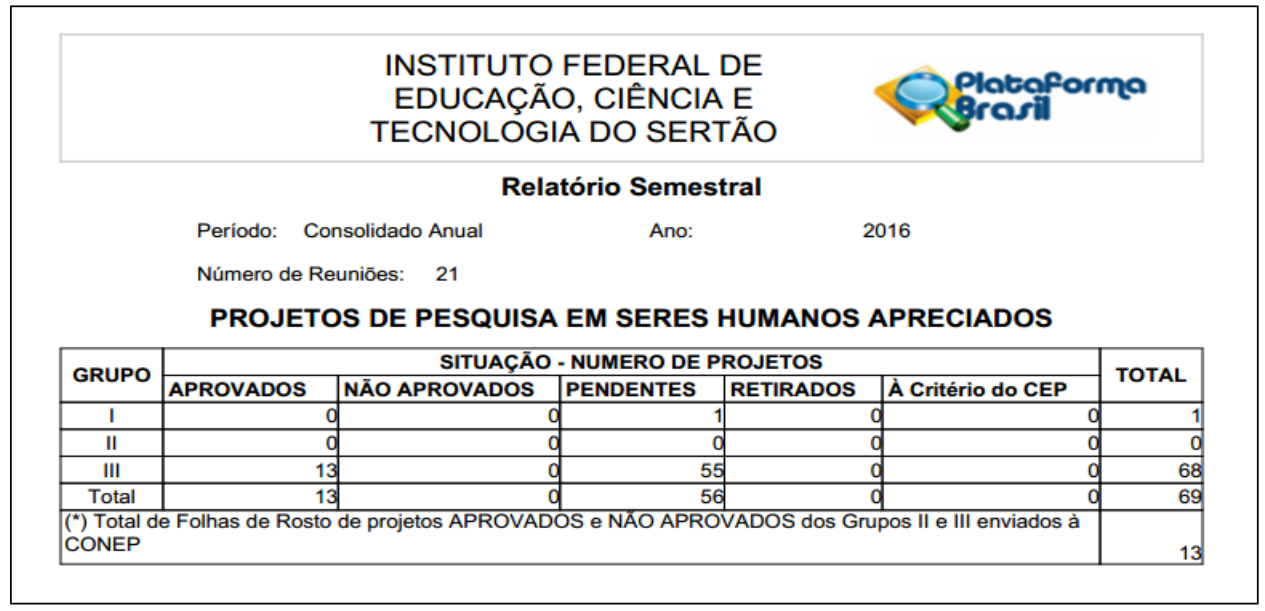

Fonte: Perfil Plataforma Brasil CEP IF Sertão-PE.

Essa figura evidencia o relacionamento entre o supracitado órgão da administração pública e os pesquisadores, os quais submeteram seus projetos de pesquisa à análise ética.

Considerando o recente o início das atividades do CEP IF Sertão-PE, o sistema de informação Plataforma Brasil mostrou ser eficaz quanto ao seu manuseio pelos membros do CEP IF Sertão-PE; bem como, pelo secretário desse colegiado, visto que a resolução $n^{\circ} 370 / 2007-C N S$ preceitua uma demanda mínima de doze (12) análises de projetos de pesquisa por ano que um comitê de ética em pesquisa deverá analisar. Essa eficácia evidencia-se, também, pela constatação do tempo médio 
SANTOS, M. A. B.; SILVA, M. B. (2018)

O Marketing de Relacionamento com o Cidadão como instrumento da análise Ética da Pesquisa

utilizado para avaliação dos projetos de pesquisa por esse colegiado, conforme o quadro demonstrativo de indicadores desse colegiado:

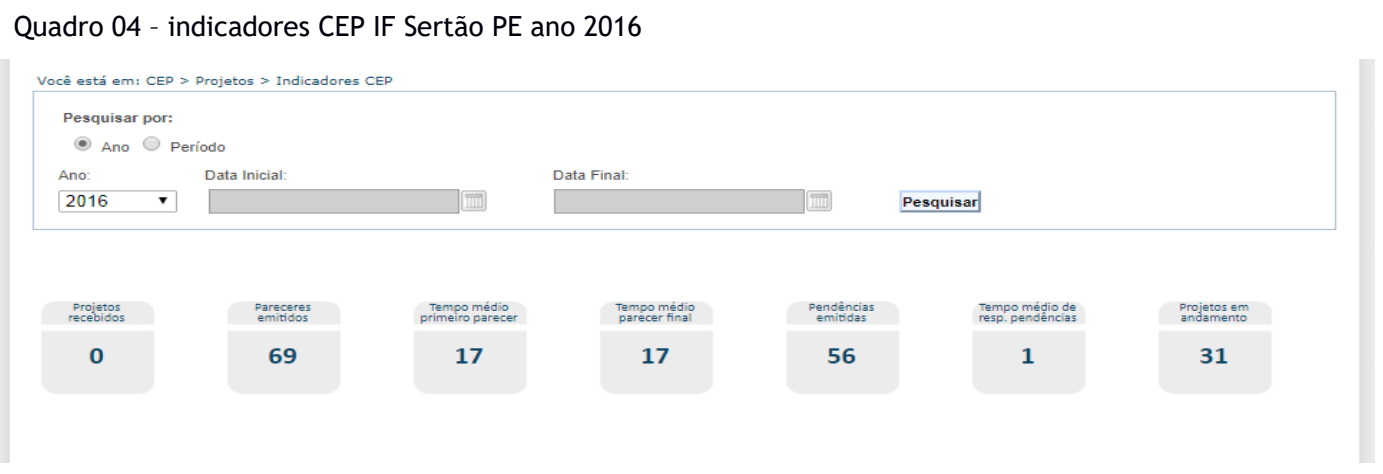

Fonte: Perfil Plataforma Brasil CEP IF Sertão-PE

Com efeito, considerando que a norma operacional $n^{\circ}$ 01/2013-CNS preceitua um período máximo de trinta (30) dias para avaliação de um projeto de pesquisa, o CEP IF Sertão-PE utilizou um tempo médio estimado em dezessete (17) dias para elaboração do primeiro parecer e parecer final de cada projeto de pesquisa.

Quanto aos projetos de pesquisa aprovados por esse colegiado, a resolução n466/2012-CNS preceitua que o CEP IF Sertão-PE torna-se corresponsável por eles. Dessa forma, os pesquisadores são notificados, através de correio eletrônico, quanto aos prazos para entrega dos relatórios parcial e final da execução das atividades da pesquisa. Portanto, o CEP IF Sertão PE poderá verificar se o pesquisador respeitou todos os princípios éticos na execução da pesquisa, através da análise desses relatórios.

Ademais, O CEP IF Sertão PE poderá receber notificações de eventos adversos ou fatos inesperados na execução da pesquisa por parte dos participantes dela. Acerca disso, a aprovação ética de um projeto exige que o pesquisador, antes de executar a pesquisa, colha o consentimento do participante, mediante a apresentação do TCLE contendo todas as informações da pesquisa, seus riscos e benefícios.

Nesse sentido, o modelo de TCLE (termo circunstanciado de livre esclarecimento) adotado pelo CEP IF Sertão PE transcreve, no seu corpo de texto, as contas de endereço eletrônico do CEP IF Sertão-PE e CONEP acompanhados dos respectivos contatos telefônicos desses órgãos, para que os sujeitos da pesquisa não fiquem desprotegidos, durante a execução da pesquisa, quanto aos seus direitos.

Além da proteção aos participantes da pesquisa, a atuação do CEP IF Sertão-PE visa proteger a instituição proponente e o pesquisador. Nesse sentido, a análise ética da pesquisa exige um maior rigor na sua execução, evitando que ela possa se utilizar de procedimentos antiéticos que possam ocasionar seu questionamento em vias judiciais, de forma a comprometer a instituição proponente e o pesquisador, bem como salvaguardar a imagem desses atores perante a comunidade acadêmica e sociedade.

Nessa concepção, a atuação do CEP IF Sertão-PE vai além dessas proteções. A presença de um comitê de ética em uma instituição contribui para elevação da eficácia e qualidade científica de 
SANTOS, M. A. B.; SILVA, M. B. (2018)

O Marketing de Relacionamento com o Cidadão como instrumento da análise Ética da Pesquisa

seus projetos de pesquisa, pois além de serem aprovados no âmbito científico, há a garantia de que essa pesquisa está isenta de quaisquer malefícios para seus participantes, pois a aprovação ética da pesquisa pressupõe a adequação de seus procedimentos às resoluções e legislação correlatas.

Dessa forma, há o estabelecimento de parceria e a instituição proponente para fins de um aprimoramento e desenvolvimento nas pesquisas desenvolvidas em seu âmbito.

Para tanto, o sistema de informação Plataforma Brasil proporcionou transparência ao relacionamento entre CEP IF Sertão-PE e pesquisadores, durante a análise ética de cada projeto de pesquisa; por conseguinte, dando publicidade aos atos praticados por esse colegiado, conforme figura ilustrativa da tramitação de um desses projetos de pesquisa:

Quadro 05 - demonstração do relacionamento pesquisador e CEP IF Sertão-PE

\begin{tabular}{|c|c|c|c|c|c|c|c|c|}
\hline Apreciação & Data/Hora & Tino Trâmite & Keตีอ & Autor & Perfil & Origem & Destino & Intormoñ̄อ \\
\hline PO & $\begin{array}{l}08 / 12 / 2016 \\
17: 04: 11\end{array}$ & $\begin{array}{l}\text { Submetido para } \\
\text { avaliaçẫo do } \\
\text { CFIo }\end{array}$ & 2 & $\begin{array}{l}\text { Rodolfo } \\
\text { de } \\
\text { Moraes }\end{array}$ & $\begin{array}{l}\text { Pesquisador } \\
\text { Principal }\end{array}$ & PESQUISADOR & $\begin{array}{l}\text { Instituto Federal de Educ ação, } \\
\text { Ciéncia e Tecroologia do Sertäo }\end{array}$ & \\
\hline PO & & & & \begin{tabular}{|l|} 
Peix oto \\
Cristiano \\
Dias Da
\end{tabular} & & $\begin{array}{l}\text { Instituto Federal de Educacacão, } \\
\text { Ciência e Tecnologia do Sertăo }\end{array}$ & & \\
\hline Po & $18: 32: 30$ & liberado & 1 & $\begin{array}{l}\text { Dias Da } \\
\text { Silva }\end{array}$ & Coordenador & $\begin{array}{l}\text { Ciencia e Tecnologia do Sertao } \\
\text { Pernambuc ano - IF SERTÄO-PE }\end{array}$ & PESQUISADOR & \\
\hline PO & \begin{tabular}{|l}
$05 / 12 / 2016$ \\
$18: 28: 05$
\end{tabular} & $\begin{array}{l}\text { Parecer do } \\
\text { Colegiado } \\
\text { Editado }\end{array}$ & 1 & $\begin{array}{l}\text { Cristiano } \\
\text { Dias Da } \\
\text { Silva }\end{array}$ & Coordenador & 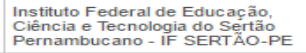 & $\begin{array}{l}\text { Instituto Federal de Educação, } \\
\text { Cléncia e Tecnologia do Sonttä. } \\
\text { Pernambucano - IF SERT ÂO-PE }\end{array}$ & \\
\hline PO & $\begin{array}{l}02 / 12 / 2016 \\
18: 43: 24\end{array}$ & $\begin{array}{l}\text { Parecer do } \\
\text { colegiado } \\
\text { emitido }\end{array}$ & 1 & $\begin{array}{l}\text { Ednaldo } \\
\text { Gomes } \\
\text { da Silva }\end{array}$ & $\begin{array}{l}\text { Membro do } \\
\text { CEP }\end{array}$ & $\begin{array}{l}\text { Instituto Federal de Educação, } \\
\text { Ciência e Tecnologia do Sêrtăo } \\
\text { Pernambuc ano - IF SERTAO-PE }\end{array}$ & $\begin{array}{l}\text { Instituto Federal de Educação, } \\
\text { Ciência e Tecnologia do Sertăo } \\
\text { Pernambucano - IF SERTÂO-PE }\end{array}$ & \\
\hline PO & $\begin{array}{l}01 / 12 / 2016 \\
15: 51: 18 \\
\end{array}$ & $\begin{array}{l}\text { Parecer do } \\
\text { relator emitido }\end{array}$ & 1 & $\begin{array}{l}\text { Ednaldo } \\
\text { Gomes } \\
\text { da Silva }\end{array}$ & $\begin{array}{l}\text { Membro do } \\
\text { CEP }\end{array}$ & $\begin{array}{l}\text { Instituto Federal de Educacão, } \\
\text { Ciência e Tecrnologia do Sertão } \\
\text { Pernambucano- IF SERTÄO-PE }\end{array}$ & $\begin{array}{l}\text { Instituto Federal de Educação, } \\
\text { Ciencia e Tecnologia do Sertão } \\
\text { Pernambucano - IF SERTÄO-PE }\end{array}$ & \\
\hline PO & $\begin{array}{l}\text { 01/12/2016 } \\
14: 36: 14\end{array}$ & $\begin{array}{l}\text { Aceitação de } \\
\text { Elaboracãa de } \\
\text { Relatoria }\end{array}$ & 1 & $\begin{array}{l}\text { Ednaldo } \\
\text { Gomes } \\
\text { da Silva }\end{array}$ & $\begin{array}{l}\text { Membro do } \\
\text { CEP }\end{array}$ & $\begin{array}{l}\text { Instituto Federal de Educaca äo, } \\
\text { Ciência e Tecnologia do Sertão } \\
\text { Pernambucano - IF SERTÂO-PE }\end{array}$ & 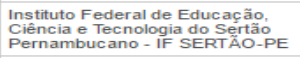 & \\
\hline PO & $\begin{array}{l}\text { 22/11/2016 } \\
00: 36: 15\end{array}$ & $\begin{array}{l}\text { Confirmação de } \\
\text { Indicação de } \\
\text { Relatoria }\end{array}$ & 1 & $\begin{array}{l}\text { Cristiano } \\
\text { Dias Da } \\
\text { Silva }\end{array}$ & Coordenador & $\begin{array}{l}\text { Instituto Federal de Educacanao, } \\
\text { Ciência e Tecnologia do Sêrtão } \\
\text { Pernambucano - IF SERTAO-PE }\end{array}$ & $\begin{array}{l}\text { Instituto Federal de Educacaão, } \\
\text { Ciência e Tecnologia do Sertão } \\
\text { Pernambucano - IF SERTAOO-PE }\end{array}$ & \\
\hline PO & \begin{tabular}{|l|}
$21 / 11 / 2016$ \\
$18: 55: 55$
\end{tabular} & $\begin{array}{l}\text { Indicação de } \\
\text { Relatoria }\end{array}$ & 1 & $\begin{array}{l}\text { Cristiano } \\
\text { Dias Da } \\
\text { Silva }\end{array}$ & Coordenador & $\begin{array}{l}\text { Instituto Federal de Educação, } \\
\text { Ciência e Tecrnologia do Sertão } \\
\text { Pernambucano - IF SERTAO-PE }\end{array}$ & $\begin{array}{l}\text { Instituto Federal de Educação, } \\
\text { Ciência e Tecrnologia do Sertão } \\
\text { Pernambucano-IF SERTÂ-PE }\end{array}$ & \\
\hline PO & \begin{tabular}{|l|}
$21 / 11 / 2016$ \\
$18: 51: 58$
\end{tabular} & $\begin{array}{l}\text { Recusa de } \\
\text { Indicacáa de } \\
\text { Relatoria }\end{array}$ & 1 & $\begin{array}{l}\text { Cristiano } \\
\text { Dias Da } \\
\text { Silva }\end{array}$ & Coordenador & $\begin{array}{l}\text { Instituto Federal de Educacãa. } \\
\text { Ciência e Tecnologia do Sertão } \\
\text { Pernambucano - IF SERTÂO-PE }\end{array}$ & $\begin{array}{l}\text { Instituto Federal de Educacâå, } \\
\text { Ciência e Tecnologia do Sertăo } \\
\text { Pernambucano - IF SERTÂO-PE }\end{array}$ & $\begin{array}{l}\text { Este trabalha está sendo } \\
\text { mudado de relator } \\
\text { porque ver mais } \gg \geqslant\end{array}$ \\
\hline \multirow[t]{2}{*}{ PO } & \begin{tabular}{|l|}
$21 / 11 / 2016$ \\
$18: 44: 45$
\end{tabular} & $\begin{array}{l}\text { Indicacáa a de } \\
\text { Relatoria }\end{array}$ & 1 & $\begin{array}{l}\text { Cristiano } \\
\text { Dias Da } \\
\text { Silva }\end{array}$ & Coordenador & $\begin{array}{l}\text { Instituto Federal de Educacacaoo, } \\
\text { Ciência e Tecnologia do Sertão } \\
\text { Pernambucano - IF SERTÁO-PE }\end{array}$ & $\begin{array}{l}\text { Instituto Federal de Educação, } \\
\text { Ciência e Tecnologia do Sertäo } \\
\text { Pernambucano - IF SERTAOO-PE }\end{array}$ & \\
\hline & \multicolumn{8}{|c|}{ Ocorrência 1 a 10 de 19 registro(s) } \\
\hline
\end{tabular}

Fonte: Perfil Plataforma Brasil CEP IF Sertão-PE

Além da de subsidiar a análise ética da pesquisa, esse sistema de informação constitui um banco de dados das pesquisas submetidas à análise ética. Nessa perspectiva, todos os documentos relativos aos projetos de pesquisas analisados pelo CEP IF Sertão-PE estão disponíveis para eventuais consultas; com fins de subsidiar essas consultas, cada projeto submetido recebe um número CAAE1.

Nesse contexto, a estratégia de relacionamento com o cidadão (pesquisador), via Plataforma Brasil, mostra-se eficiente e eficaz para o cumprimento do propósito do sistema CEP/CONEP: regulamentação ética da pesquisa com seres humanos, mas que ainda precisa ser adaptada às peculiaridades das pesquisas no campo das ciências sociais e humanas.

Essa estratégia poderá ser complementada por outras formas de relacionamento com o cidadão pesquisador: telefone de contato ou e-mail do CEP IF Sertão-PE, ou visita à secretaria desse colegiado para um atendimento diferenciado. 
SANTOS, M. A. B.; SILVA, M. B. (2018)

O Marketing de Relacionamento com o Cidadão como instrumento da análise Ética da Pesquisa

\section{Conclusão}

A aprovação ética da pesquisa científica demonstra a humanização dos procedimentos adotados pelo pesquisador. Nesse contexto, imprescindível refletir sobre as condições e circunstâncias das pessoas que serão submetidas aos procedimentos de sua pesquisa.

A respeito disso, o sistema CEP/CONEP possibilita o exercício do direito fundamental da dignidade da pessoa humana; sobretudo, os participantes da pesquisa.

Sendo assim, o benefício pretendido pela pesquisa não poderá prevalecer sobre os direitos e garantias das pessoas que aceitaram dela participar, pois desarrazoável ou até imoral, passível de apuração nas esferas civil ou criminal, uma pesquisa que submeta seres humanos a procedimentos vexatórios ou danosos com fins proporcionar benefícios a outros seres humanos.

Ademais, o compromisso do sistema CEP/CONEP, como pontuado, é salvaguardar os direitos e a dignidade dos sujeitos da pesquisa; embora não possua poder de polícia fiscalizatório. Diante do exposto, os CEPs tornam-se corresponsáveis pelas pesquisas aprovadas, impedindo que a execução dessas pesquisas possa comprometer a dignidade do participante dela.

Porquanto, esse sistema é um instrumento de defesa dessa dignidade pertencente às pessoas, muitas vezes, desconhecedoras de seus direitos, os quais podem ser eventualmente violados.

Considerando a importância da pesquisa científica para o desenvolvimento da sociedade, o conhecimento e divulgação desse relacionamento tornam-se relevantes, pois contribuem para que a pesquisa, aprovada sobre o aspecto ético, cumpra sua função social, sem desrespeito aos direitos fundamentais dos seres humanos que dela participam.

\section{Referências}

ARAUJO, P. G; PEREIRA, J. R. Análise da aplicabilidade do modelo gerencial na administração municipal. Revista de Administração Pública, Rio de Janeiro, v. 46, n. 5, p. 1179-1199, out. 2012. Disponível em <http://www.scielo.br/scielo.php?script=sci_arttext\&pid=S0034$76122012000500001 \&$ Ing=pt\&nrm=iso>. acesso em 27 abr. 2018.

BARBOSA, A. S.; CORRALES, C. M. \& SILLBERMANN, M. Controvérsias sobre a revisão ética de pesquisas em ciências humanas e sociais pelo Sistema CEP/Conep. Revista Bioética, Brasília, vol.22, $\mathrm{n}^{\circ} 3$, setembro/dezembro 2014. Disponível em:<http://www.scielo.br/scielo.php? script=sci_arttext\&pid=S1983-80422014000300012\&lang=pt>. Acesso em 16 de junho de 2017.

BRASIL. Conselho Superior do Instituto Federal de Educação, Ciência e Tecnologia do Sertão Pernambucano. Regimento Interno, resolução n. 59, de 25 de setembro de 2015.

BRASIL. Conselho Nacional De Saúde. Resolução $\mathrm{n}^{\circ}$ 466, 2012. Disponívelem:<http://www.conselho.saude.gov.br/resolucoes/2012/Reso466.pdf>. Acesso em 05 de junho de 2017.

BRASIL. Conselho Nacional De Saúde. Norma operacional $n^{\circ}$ 13. 2013. Disponível em: <http: //conselho.saude.gov.br/web_comissoes/conep/aquivos/CNS\%20\%20Norma\%200peracional \%20001\%20-\%20conep\%20finalizada\%2030-09.pdf >. Acesso em 08 de junho de 2017. 
BRASIL. Conselho Nacional De Saúde. Resolução $\mathrm{n}^{\circ}$ 510, 2016. Disponível em:<http://www.conselho.saude.gov.br/resolucoes/2016/reso510.pdf. Acesso em 11 de junho de 2017.

BRASIL. Conselho Nacional De Saúde. Comissões CNS CONEP, 2017. Disponível em: http://www.conselho.saude.gov.br/web_comissoes/conep/index.html. Acesso em 29 de junho de 2017.

BRASIL. Emenda Constitucional $\mathrm{n}^{\circ} 19 . \quad$ Disponível em: <http://http://www2.camara.leg.br/legin/fed/emecon/1998/emendaconstitucional-19-4-junho1998-372816-norma-pl.html. Acesso em 25/04/2018.

BRASIL. LEI $\mathrm{N}^{\circ}$ 12.527. Brasília: Senado Federal, 2011. Disponível em: <http://www.planalto.gov.br/ccivil_03/_ato2011-2014/2011/lei/l12527.htm>. Acesso em 25 de abril de 2018.

BRASIL. Ministério da Saúde. Conselho Nacional de Saúde. Manual operacional para comitês de ética em pesquisa. Brasília: Editora do Ministério da Saúde, 2006.

BRASIL. Secretaria Municipal de Saúde de São Paulo. Manual Sobre Ética em Pesquisa Com Seres Humanos, 2004. Disponível em: <http://pesquisa.bvsalud.org/sms/resource/pt/sms-836. Acesso em 27 de junho de 2017.

BRASIL. Centro universitário do estado do Pará. Comitê de ética em pesquisa. Disponível em:< http://www.cesupa.brsaibamais/cep/cep.asp>. Acesso em: 07 de junho de 2017.

DEMO, G. \& PESSÔA, R. CRM na Administração Pública: desenvolvimento e validação de uma escala de relacionamento com o cidadão. Revista administração pública, Rio de Janeiro, vol.49, $n^{\circ} 3$, maio/ junho 2015, página 678. Disponível em: < http://www.scielo.br/scielo.php?script=sci_arttext\&pid. Acesso em 08 de junho de 2017.

GONÇALVES, C. A. \& FILHO, C. G.Tecnologia da informação e marketing como, obter clientes e mercado. Revista de Administração de Empresas, São Paulo, vol.35, n4, julho/agosto 1995. Disponível em:<http://www.scielo.br/scielo.phpscript=sci_arttext\&pid=\$003475901995000400004>. Acesso em 10 de junho de 2017. Acesso em 09 de junho de 2017.

LARA, R. D.; GOSLING, M. S. Um modelo de gestão do relacionamento entre os cidadãos e a administração pública. READ. Revista eletrônica de administração, Porto Alegre, vol.22, $\mathrm{n}^{\circ} 2$, maio/agosto 2016. Disponível em:<http://www.scielo.br/scielo.php? pid=S1413232016000200333\&script=sci_artteext.> Acesso em 10 de junho de 2017. Acesso em 10 de junho de 2017.

REIS, A. C. F. Marketing Cultural e Financiamento da Cultura. 1.ed. São Paulo: Ed. Thompson Oliveira, 2002.

SALIBY, P. E. O Marketing de relacionamento: o novo Marketing da nova era competitiva. Revista de administração de empresas, São Paulo, vol.37 n³, julho/setembro1997. Disponível em:<http: / / wwwscielo.br/scielo.php?script=sci_arttext\&pid=S00347501997000300011\&lang-pt>. Acesso em 14 de junho de 2017.

SCHUCH.P \& CERES, V. Pesquisas envolvendo seres humanos: reflexões a partir da Antropologia Social. Revista de Saúde Coletiva, Rio de Janeiro, vol.25, $\mathrm{n}^{\circ 3}$, julho/setembro2015. Disponível em: <http: / / www.scielo.br/scielo.php?script=sci_arttext\&pid=S0103-73312015000300779\&lang=pt >. Acesso em 09 de junho de 2017.

KOTLER, P \& ARMSTRONG, G. Princípios de Marketing. 9.ed. São Paulo: Ed. Pearson education do Brasil, 2006, p.474. 